
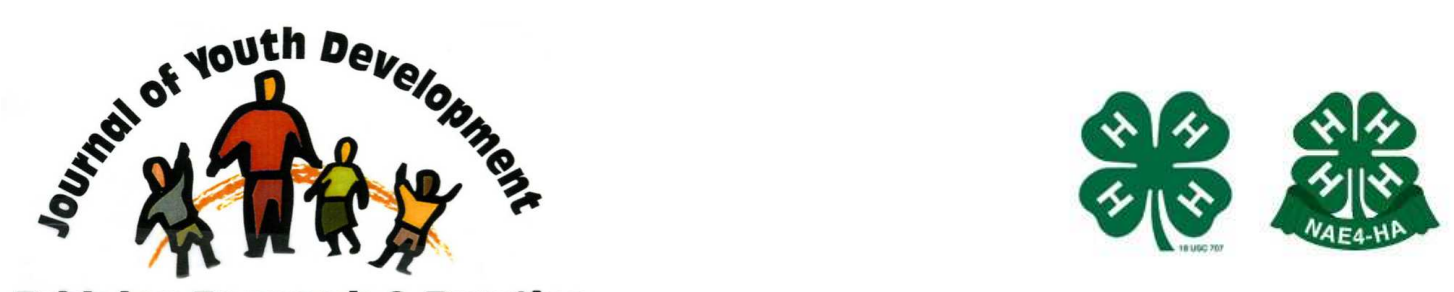

Bridging Research \& Practice

\title{
Sports and Youth Development Programs: Theoretical and Practical Implication of Early Adolescent Participation in Multiple Instances of Structured Out-of-School (OST) Activity
}

\author{
Nicole Zarrett \\ Institute for Applied Research in Youth Development \\ Tufts University \\ Medford, MA \\ nicole.zarrett@tufts.edu \\ Jack Peltz \\ Institute for Applied Research in Youth Development \\ Tufts University \\ jack.merless@tufts.edu \\ Kristen Fay \\ Institute for Applied Research in Youth Development \\ Tufts University \\ kristen.e.fay@tufts.edu \\ Yibing Li \\ Institute for Applied Research in Youth Development \\ Tufts University \\ yibing.li@tufts.edu \\ Jacqueline V. Lerner \\ Institute for Applied Research in Youth Development \\ Boston College Lynch School of Education \\ lernerj@bc.edu \\ Richard M. Lerner \\ Institute for Applied Research in Youth Development \\ Tufts University \\ richard.lerner@tufts.edu
}




\title{
JOURNAL OF YOUTH DEVELOPMENT \\ bridging research and practice

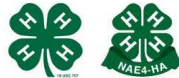

\section{Sports and Youth Development Programs: Theoretical and Practical Implication of Early Adolescent Participation in Multiple Instances of Structured Out-of-School (OST) Activity}

Nicole Zarrett, Jack Peltz, Kristen Fay, Yibing Li, Richard M. Lerner

Tufts University

Jacqueline $\mathrm{V}$. Lerner

Boston College Lynch School of Education

\begin{abstract}
Among today's youth, the most ubiquitous OST activity is sports. However, many of these youth are also participating in at least one other OST activity along with their participation in sports. Using longitudinal data from 1,622 youth (56.8\% female) from the first three waves (Grades 5, 6, and 7) of the 4-H Study of Positive Youth Development (PYD), we employed a pattern-centered approach to assess differences in adolescent functioning depending on what types of OST activities youth were participating in along with their sports participation.

Our findings suggest that youth benefit from their sports participation differently depending on what other types of additional activities they participate in during their out-of-school time. In particular, a participation pattern characterized by high participation in sports and Youth Development Programs was found to be the most effective activity profile for promoting PYD and preventing youth problems. Implications of these findings in research and practice are discussed.
\end{abstract}




\section{Introduction}

Theory and research converge in pointing to structured out-of-school (OST) activities as important assets in the positive development of youth (Chaskin \& Baker, 2006; Mahoney, Larson, \& Eccles, 2005). Participation in structured OST activities has been associated with higher academic and occupational achievement, reduced rates of delinquency, and the development of identity and initiative (e.g., Barber, Eccles, \& Stone, 2001).

Research regarding youth activities has examined activity participation in various ways, including time devoted to a particular activity domain, and aggregate scores of the number of activities in which youth engage. These studies have demonstrated that different activities can and often do influence youth development differently (Eccles, Barber, Stone, \& Hunt, 2003; Larson, Hansen, \& Moneta, 2006;), and the more activities youth are involved in, the higher their scores on various indicators of positive youth development (PYD) (e.g., Mahoney, 2000; Zaff, Moore, Papillo, and Williams, 2003).

However, whether we count the number of activities youth are involved in, or consider the different types of activities in which youth engage, there is increasing evidence that within any one school year a large percentage of youth participate in more than one OST activity context (Shanahan \& Flaherty, 2001; Theokas, Lerner, Lerner, \& Phelps, 2006). Some researchers have begun to examine how youth organize their out-of-school time across multiple structured and unstructured activities during the course of a day, week, or year. Their findings suggest that across activities there are a variety of common activity participation patterns among adolescents. Moreover, the relation of participation in activities to each other varies in the degree to which they foster development (Bartko \& Eccles, 2003; Peck, Roeser, \& Zarrett, in press; Zarrett, 2006). Therefore, considering youth patterns of participation across activities is important for understanding what activities, in combination with one another, best promote PYD (Bartko \& Eccles, 2003; Zarrett, 2006).

Among today's youth, the most ubiquitous OST activity is sports (Larson \& Verma, 1999; Theokas et al., 2006; Ewing, Seefeldt, \& Brown, 1996). In comparison to non-participants, youth who participated in organized sports reported greater increases in liking school between $10^{\text {th }}$ and $12^{\text {th }}$ grades, received more frequent educational and occupational support, had higher academic performance in high school, had more total years of tertiary education by age 25 , and attained a job at age 24 that offered autonomy and a promising future (Barber, et al., 2001). Female athletes reported lower rates of sexual activity and/or early sexual intercourse, net of the influence of race, age, SES, quality of family relations, and participation in other extracurricular activities (e.g., Miller, Sabo, Farrell, Barnes \& Melnick, 1998). Participation in sports was also linked to lower use of cigarettes, marijuana, cocaine, and "other drugs" (Page, Hammermeister, Scanlon, \& Gilbert, 1998), lower rates of depression, and lower incidence of suicidal behavior; these associations were not found with participation in art, community service, or school activities (e.g., Barber, et al., 2001).

However, many of these youth are also participating in at least one other OST activity along with their participation in sports. Little research has explored how sports participation may benefit youth differently depending on what other activities they participate in during their outof-school time. The present study extends previous research (Theokas et al., 2006) on the benefits of sports participation by using a more holistic, pattern-centered approach to identify, and then compare: 
1. youth with different types of common $7^{\text {th }}$ grade sport-dominant activity patterns to each other; and,

2. to youth with other non-sport related patterns, on multiple indicators of functioning, including PYD, Contribution, risk behavior, and depression.

\section{Method}

Full details of the methodology of the 4-H Study have been presented in earlier reports (e.g., see Jelicic, Bobek, Phelps, Lerner, Lerner, in press; Lerner, Lerner, Almerigi, et al., 2005). Accordingly, we present here those features of methodology pertinent to the focus of the present report.

\section{Participants}

This report is based on a subsample of 1,622 of the original 3,500 adolescents ( $56.8 \%$ female; 43.2\% male) from the 4-H Study of Positive Youth Development (Lerner et al., 2005), and includes the sample of youth who participated in at least two of the first three waves of assessment $\left(5^{\text {th }}, 6^{\text {th }}\right.$, and $7^{\text {th }}$ grades). In the first wave of data collection, participants in the 4-H study came from sites located in 13 states that provided regional, rural-urban, racial/ethnic, and religious diversity. Participants were 1,722 fifth grade adolescents ( $48 \%$ males, mean age $=11.1$ years, $\mathrm{SD}=.52 ; 52 \%$ female, mean age $=10.9$ years, $\mathrm{SD}=.45$ ) and 1,139 of their parents. At Wave 2, youth were retested during the sixth grade. In addition, in order to control for the influence of prior testing on the findings, an additional sample was added. A total of 1,872 sixth graders $(43 \%$ male, mean age $=12.2$ years, $\mathrm{SD}=.07 ; 57 \%$ females, mean age $=12.1$ years, $\mathrm{SD}=.33$ ) and over 1,300 of their parents participated in Wave 2 data collection, sampled from 18 states across the nation. At Wave 3, in addition to retesting Wave 1 and Wave 2 participants, a new group of participants was again added to the sample. A total of 1,600 youth ( $40 \%$ male, mean age $=13.2$ years, $S D=.08 ; 60 \%$ female, mean age $=13.2$ years, $\mathrm{SD}=.90)$ and over 1,182 of their parents from 17 states were tested.

The sample was largely European American (63.7\%), but included some variation in race/ethnicity (Latino/a $=11.9 \%$, African American $=6.1 \%$, Asian American $=3.7 \%$, Native American $=2.3 \%$, Multi-ethnic $/$ racial $=4.2 \%$, Other $=.6 \%$ ). Because the autocorrelation for the family per capita income between the three waves was highly significant $(r=.81, .87$, $.89 p<.001$, for Waves 1 and 2, Waves 2 and 3, and Waves 1 and 3, respectively), the average family per capita income was computed for each participant, based on available data $(1,2$, or 3 waves). The mean of this composite variable was $\$ 13,996$ ( $S D=\$ 9,241)$.

\section{Measures}

Indexing Structured OST Activities. As shown in Table 1, the present report categorized 21 OST activities into eight activity types for our analyses. The list of activities included Youth Development (YD) programs such as 4-H and Boys \& Girls Club, after-school clubs (e.g., school government, chess club), team and individual sports, the performing arts (e.g., music, drama), arts and crafts, service activities (e.g., volunteering), and paid work. At Grade 7, youth reported the amount of time they spent participating in each activity during the current school year/summer $(0=$ never to $5=$ every day $)$. 
Table 1

The 21 Structured Activities and Eight Activity Types in Grade 7

\begin{tabular}{|l|l|}
\hline Type of Activity & Individual Activities \\
\hline YD Programs & 4-H Club \\
& Boys Scouts and Girl Scouts: \\
& YMCA and YWCA \\
& Big Brothers and Big Sisters \\
Boys and Girls Club
\end{tabular}

Indexing Adolescent Functioning. We examined the relation of participation to various indicators of adolescent well-being. We first examined overall PYD, shown to be a second-order latent construct constituted by psychological, behavioral, and social characteristics reflecting "Five C's:" competence, confidence, character, connection, and caring (Lerner et al., 2005). In turn, research suggests that among thriving youth a sixth C, Contribution (e.g., to family and community) develops (Lerner et al., 2005). Therefore, we also examined the degree to which youth contributed to their families/communities (Contribution), measured as a composite score of twelve items divided into four subsets: leadership, service, helping, and ideology.

Other indicators of functioning assessed included: participation in risk behaviors, including questions regarding the frequency of substance use (e.g., alcohol) and other delinquent behaviors (e.g., "how many times have you hit or beat up someone?") in the last year, and depressive feelings (CES-D; Radloff, 1977), such as how often a youth felt sad during the past week. The construction, reliability, and validity of these measures are described in Lerner et al. (2005). 


\section{Results}

We first explored adolescents $7^{\text {th }}$ grade activity participation across multiple OST activities using Cluster Analysis (Ward's Method, Ward, 1963). This pattern-centered approach enabled us to identify the common activity participation patterns of youth, and more specifically, to determine the different types of sports-dominant activity patterns in which youth engage. Within the 10 cluster solution that emerged, we found three different types of sports-dominant participation profiles. In the first of these sports clusters, youth were more involved in sports relative to their participation in other activities (they had lower than average reports of time spent in all other activities measured). For ease of presentation, this group of youth was referred to as the "Sports-Only" profile, but the reader should keep in mind that a brief one or two word label cannot adequately capture the entire profile of activity involvement.

The second sport cluster, "Sport+YD" is distinguished by high rates of participation in both sports and Youth Development programs, and by slightly above average time spent volunteering and in religious-based activities. The third sport cluster, which we named the "High-Engaged" group, is characterized by spending above average time in all the activities measured. In fact, the time High-Engaged youth devoted to sport is similar to the amount of time Sport+YD youth spent in sports; both groups spent more time in sport than youth in all other groups including the Sport-Only youth (see Table 2 for means). A fourth activity profile, "Work+Religion," involved youth who spent considerably less time devoted to sports in comparison to the other sport profiles, but was characterized by above average participation in sport relative to the non-sport profiles that emerged. Therefore, in our comparison analyses we also considered these youth as having another type of sport-dominant activity profile.

Six non-sport activity profiles also emerged. The fifth activity profile included youth characterized by high involvement in school clubs, "Clubs." The sixth cluster was primarily characterized by youth who participated in performing arts, "PerfArt," and the seventh profile was characterized by youth who mainly participated in arts and crafts, "ArtCraft." The eighth profile included youth who spent much of their time in religious-related activities, "Relig," and the ninth profile, "Work," included youth who spent most of their free time in paid work. The tenth profile, "Low-Engaged," involved youth who spent considerably lower than average time in all activities we examined.

For our comparative analyses, the youth from several of these non-sport OST activity profiles were combined and considered the "Other-Activities" profile, with the exception of the "LowEngaged" youth and the "Work" youth. Youth who had either of these types of activity profiles were examined separately because of previous research suggesting that youth who spend excessive time in paid work and those who spend little time in structured OST activities fare worse than other youth on indicators of positive functioning (e.g., Bachman \& Schulenberg, 1993; Zarrett, 2006) (see Figure 1). 


\begin{tabular}{|c|c|c|c|c|c|c|c|c|c|c|c|}
\hline \multicolumn{12}{|c|}{$\begin{array}{c}\text { Table } 2 \\
\text { Means and Standard Deviations of Adolescents' rate of participation in activities by } t^{\text {th }} \text { Grade Activity Participation Profiles }\end{array}$} \\
\hline \multicolumn{12}{|c|}{ Cluster } \\
\hline & $\begin{array}{l}\text { High } \\
\text { Engaged }\end{array}$ & Sport+YD & Sport & $\begin{array}{l}\text { Work+ } \\
\text { Religion }\end{array}$ & School & $\begin{array}{l}\text { Performing } \\
\quad \text { Arts }\end{array}$ & $\begin{array}{l}\text { Arts \& } \\
\text { Crafts }\end{array}$ & Religion & Work & $\begin{array}{l}\text { Low } \\
\text { Engaged }\end{array}$ & Total \\
\hline Activity & $(n=67)$ & $(n=61)$ & $(n=92)$ & $(n=54)$ & $(n=56)$ & $(n=130)$ & $(n=179)$ & $(n=145)$ & $(n=200)$ & $(n=166)$ & $(\mathrm{N}=1150)$ \\
\hline YD Programs & $.82(1.78)$ & $1.75(.93)$ & $-.54(.36)$ & $-.13(.74)$ & $-.30(.62)$ & $-.28(.60)$ & $-.30(.59)$ & $-.49(.41)$ & $-.34(.58)$ & $-.46(.48)$ & $-.19(.89)$ \\
\hline Sport & $.84(1.12)$ & $.84(.77)$ & $.47(.71)$ & $.31(1.06)$ & $.10(.93)$ & $.07(.91)$ & $-.11(.92)$ & $-.24(.80)$ & $.09(.93)$ & $-1.14(.16)$ & $-.04(1.00)$ \\
\hline School & $2.17(1.94)$ & $-.29(.43)$ & $-.41(.12)$ & $-.33(.44)$ & $1.54(.70)$ & $-.15(.63)$ & $-.11(.69)$ & $-.34(.29)$ & $-.35(.26)$ & $-.42(.13)$ & $-.06(.94)$ \\
\hline Perf Arts & $.65(1.06)$ & $-.32(.83)$ & $-.76(.45)$ & $.32(1.00)$ & $-.38(.81)$ & $1.06(.52)$ & $.28(.94)$ & $-.72(.46)$ & $-.16(.92)$ & $-.76(.48)$ & $-.11(.97)$ \\
\hline Arts \& Crafts & $.77(1.19)$ & $-.14(.90)$ & $-.65(.20)$ & $-.24(.62)$ & $-.64(.25)$ & $-.51(.39)$ & $1.42(.78)$ & $-.58(.34)$ & $-.47(.45)$ & $-.64(.18)$ & $-.14(.93)$ \\
\hline Volunteer & $2.18(1.78)$ & $.24(.80)$ & $-.63(.19)$ & $.17(.73)$ & $-.48(.37)$ & $-.14(.68)$ & $-.04(.72)$ & $-.32(.47)$ & $-.04(.84)$ & $-.53(.37)$ & $-.07(.96)$ \\
\hline Religious & $.64(1.03)$ & $.25(1.03)$ & $-.87(.10)$ & $1.24(.75)$ & $-.48(.61)$ & $.23(.97)$ & $-.12(1.00)$ & $.89(.83)$ & $-.60(.48)$ & $-.80(.39)$ & $-.08(.99)$ \\
\hline Paid work & $.75(1.11)$ & $-.17(.74)$ & $-.61(.46)$ & $1.60(.48)$ & $-.34(.76)$ & $-.50(.57)$ & $-.20(.84)$ & $-.51(.55)$ & $.81(.87)$ & $-.75(.37)$ & $-.08(.97)$ \\
\hline
\end{tabular}


Figure 1

Youth $7^{\text {th }}$ Grade Activity Participation Profiles

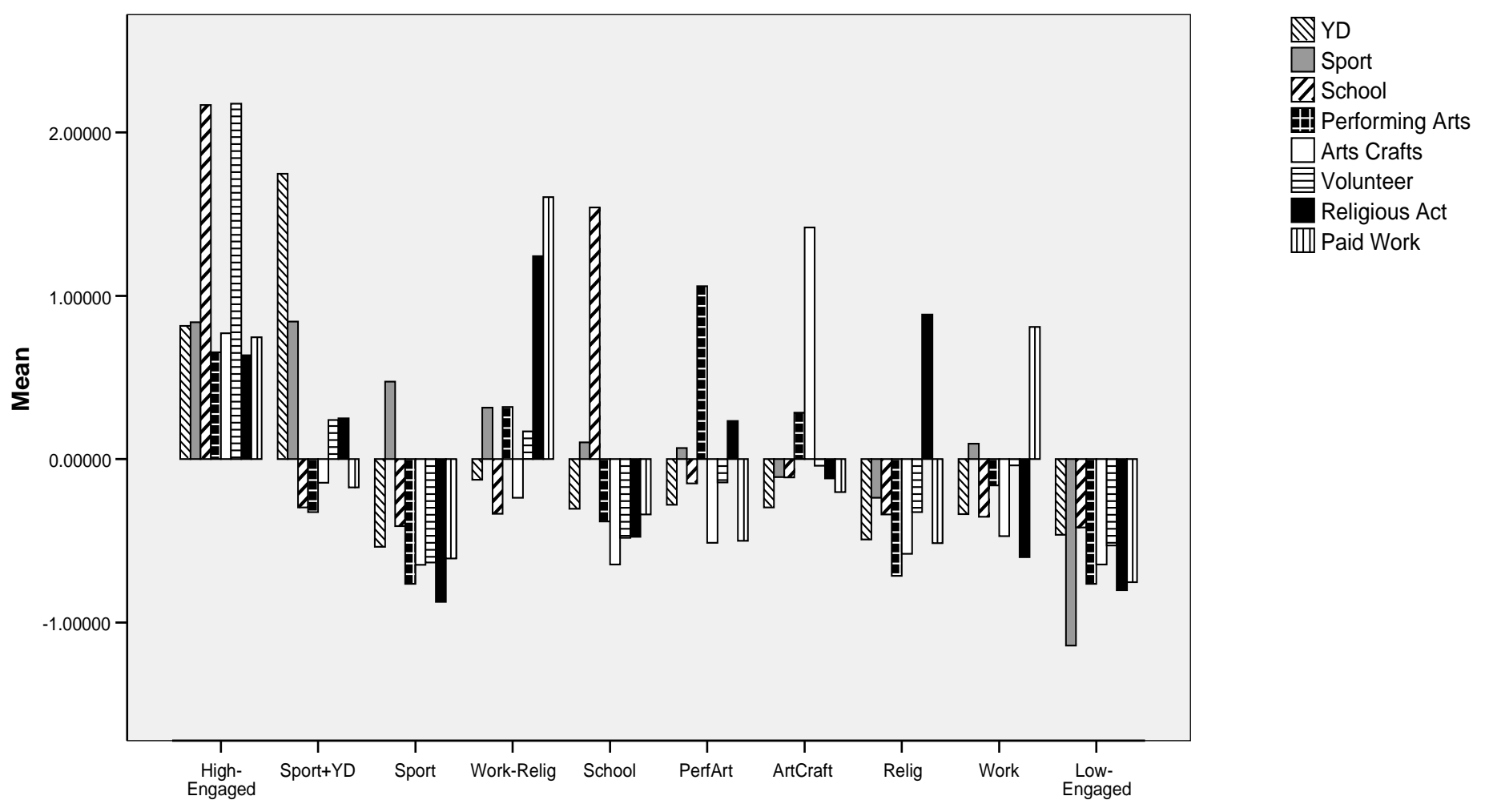

7th Grade Activity Clusters

\section{Activity Participation Patterns by Socioeconomic Status and Gender}

In our sample, SES does not appear to predict adolescents' activity choices (see Table 3 for means of the average per capita income for each activity profile). There is some variation in average per capita family income by activity profile reflective of previous research findings (e.g., that highly engaged youth have the highest family income) (Posner \& Vandell, 1999; Zarrett, 2006). However, our results of a one-way, between-group fixed effects Analysis of Variance indicated that these differences in income by activity profile were not significant, $F(9,977)$ $=.656, p=749$.

In contrast, a 2 (gender) $\times 7$ (activity pattern) chi square analysis, indicated that activity participation patterns did vary significantly by the gender of the youth $\left[x^{2}(6, N=1150)=32.35\right.$, $p<.001]$. Consistent with national data that indicate that males still participate in sports at higher rates than do females (The Woman's Sports Foundation, 2001), we found that males were significantly more likely than expected by chance to participate in the Sports-Only activity pattern while females were significantly underrepresented in the Sports-Only activity pattern. However, the sports-dominant activity patterns that also included participation in other OST activities did not significantly differ by gender. Along with their overrepresentation in the SportOnly activity pattern, males were also more likely than expected by chance to have an activity profile characterized by high amounts of time spent in paid work. Females were more likely than expected by chance to participate in both an activity pattern dominated by time spent engaging in the performing arts ("PerfArt"), and a participation pattern that mainly involved participation in arts and crafts ("ArtCrft") (see Table 3). 
Table 3

Percentage of youth who participate in each activity pattern by gender and family income

\begin{tabular}{|l|c|c|c|c|}
\hline & $\begin{array}{c}\text { Total } \\
\%\end{array}$ & $\begin{array}{c}\text { Males } \\
\%\end{array}$ & $\begin{array}{c}\text { Females } \\
\%\end{array}$ & $\begin{array}{c}\text { Average Per Capita } \\
\text { Family Income } \\
\text { (Mean) }\end{array}$ \\
\hline Activity Patterns & & & 6.2 & $\$ 15,126$ \\
\hline High Engaged & 5.8 & 6.1 & 4.7 & $\$ 12,225$ \\
\hline Sports & 5.3 & $\mathbf{1 1 . 6}+$ & 5.5 & $\$ 14,757$ \\
\hline Work+Relig & 4.7 & 5.3 & 4.3 & $\$ 13,465$ \\
\hline Clubs & 4.9 & 5.5 & 4.5 & $\$ 12,936$ \\
\hline Perf Art & 11.3 & 6.1 & $\mathbf{1 5 . 0 ^ { + }}$ & $\$ 13,676$ \\
\hline ArtCraft & 15.6 & 10.1 & $\mathbf{1 9 . 4}$ & $\$ 13,776$ \\
\hline Relig & 12.6 & 14.3 & 11.4 & $\$ 13,555$ \\
\hline Work & 17.4 & $\mathbf{2 0 . 2}$ & 15.4 & $\$ 13,4939$ \\
\hline Low Engaged & 14.4 & 15.8 & 13.5 & \\
\hline
\end{tabular}

+Significant overrepresentation in an activity by gender is indicated in bold.

\section{Are there combinations of sports and other OST Activities that are differentially associated with indicators of functioning in Grade 7?}

We considered differences in PYD, Contribution, risk behaviors, and depression by adolescents' participation profiles across multiple activities, with a focus on how the relation between sports participation and PYD may differ dependent on what types of additional activities youth participate in during their out-of-school time.

Using 2 (gender) $X 7$ (participation pattern) ANCOVAs, with average family per capita income as a covariate, differences between youth by their participation profiles were found for PYD, $F(8$, $934)=8.09, p<.001$, Contribution, $F(8,929)=25.63, p<.001$, and depressed feelings, $F(8,928)$ $=3.24, p<.01$. Post-hoc contrasts (Tukey) indicated that the High-Engaged youth scored highest on PYD, significantly higher on PYD than youth in all other activity profiles except for youth in the Sport+YD profile and youth in the Work-Religion profile, who had similarly high levels of PYD. The Sport+YD youth were significantly higher in PYD than the Sport-Only, Work, and Low-Engaged groups and were similar in PYD to youth highly involved in other structured OST activities ("Other-Activities"). Youth in the Work-Relig sport profile were significantly higher on PYD than the Sport-Only and Low-Engaged youth. In contrast, the Sport-Only youth were 
significantly lower on indicators of PYD in comparison to youth of all other activity profiles, with the exception of the Work and the Low-Engaged youth, who had similarly low levels of PYD.

The High-Engaged youth and those youth who had a profile of Sports+YD reported similar levels of Contribution, significantly higher than youth in all other groups. In contrast, youth with a Sport-Only activity profile reported significantly lower levels of Contribution in comparison to youth in all other activity profiles, except for those who had a Low-Engaged activity pattern, who reported equally low levels of Contribution.

Although youth in the Sport-Only profile reported lower PYD and Contribution than youth in the other activity profiles, they reported significantly lower depression than both the High-Engaged and Low-Engaged youth. In fact, while Sport+YD youth were not different from any other group in their experiences with depression, post-hoc tests indicated that High-Engaged youth were at greatest risk for experiencing depressed feelings. Youth of all activity profiles reported similarly low incidence of risk behaviors (see Table 4 for means).

Table 4

Means and Standard Deviations of Indicators of PYD by Grade 7 Activity Participation Profiles

\begin{tabular}{|l|c|c|c|c|c|c|c|c|}
\hline & \multicolumn{2}{|c|}{ PYD } & \multicolumn{2}{c|}{ Contribution } & \multicolumn{2}{c|}{ Risk Behavior } & \multicolumn{2}{c|}{ Depression } \\
\hline \multicolumn{1}{|c|}{ Clusters } & $M$ & $S E$ & $M$ & $S E$ & $M$ & $S E$ & $M$ & $S E$ \\
\hline High Engaged & 75.55 & 1.56 & 60.26 & 1.63 & 1.96 & .46 & 16.26 & 1.25 \\
\hline Sport+YD & 74.44 & 1.68 & 57.42 & 1.76 & 1.24 & .51 & 14.53 & 1.39 \\
\hline Sport & 67.88 & 1.37 & 43.82 & 1.44 & 1.54 & .42 & 11.96 & 1.15 \\
\hline Work+Religious & 73.11 & 1.79 & 53.07 & 1.84 & 1.50 & .53 & 12.52 & 1.44 \\
\hline School & 74.34 & 1.75 & 50.97 & 1.82 & 1.71 & .52 & 13.09 & 1.46 \\
\hline Performing Arts & 72.16 & 1.15 & 50.90 & 1.20 & 1.39 & .34 & 12.73 & .93 \\
\hline Arts/Crafts & 71.86 & .99 & 51.96 & 1.03 & 1.18 & .30 & 13.03 & .80 \\
\hline Religious & 70.95 & 1.06 & 48.32 & 1.11 & 1.74 & .31 & 11.87 & .87 \\
\hline Work & 70.05 & .91 & 49.65 & .95 & 2.02 & .27 & 12.58 & .76 \\
\hline Low Engaged & 65.72 & 1.04 & 40.59 & 1.07 & 1.97 & .31 & 15.69 & .83 \\
\hline
\end{tabular}

Note: All reported means and standard errors are net the effects of gender and average per capita family income. 


\section{Discussion}

Among the wide array of activities in which youth choose to participate, almost two-thirds of $7^{\text {th }}$ graders nationwide are participating in sports (Larson \& Verma, 1999; Theokas et al., 2006). Our pattern-centered analyses indicated that among these sport participants, many combine their sport participation with one or more additional OST activities. Accordingly, our study examined differences in adolescent functioning depending on what youth were doing in addition to their sports participation. In support of previous research (e.g., Zarrett, 2006), our findings suggest that youth benefit from their sports participation differently, depending on what other types of additional activities they participate in during their out-of-school time.

First, similar to research that measured participation using an aggregate score of the number of activities in which youth participated (e.g., Zaff et al., 2003), our findings indicated that youth highly engaged in a variety of activities ("High-Engaged") along with their sports participation were faring well on multiple indicators of positive functioning. Some researchers have proposed that participation in multiple OST activities is most beneficial for youth because engagement in such a variety of activities is presumed to provide access to a larger and more diverse group of social supports, opportunities to master a variety of competencies, and to cope with challenging tasks (Mahoney, 2000). However, using a pattern-centered approach, we found another sportdominant activity pattern that was just as beneficial to youth as the High-Engaged pattern. Specifically, those youth who had a Sports+YD activity pattern fared just as well as the HighEngaged youth on PYD, Contribution, and problem behaviors. Moreover, the Sports+YD group had lower depression scores than the High-Engaged youth. Therefore, a key "take away" message for practitioners is that Sports+YD is one of the most effective sport-dominant OST activity configuration for promoting positive development and preventing youth problems.

Accordingly, the present findings not only suggest benefits of combining other activities with participation in sports, but also that the type of sport setting provided youth may be another important factor for youth to benefit from their participation. For example, in contrast to the Sport-Only youth, it may be that the Sport+YD youth were participating primarily in the sport activities provided by their YD program (e.g., YMCA). YD settings are typically focused on providing youth with highly safe and structured environments, positive mentors, and positive overarching goals. For example, 4-H is a "community of young people across America who are learning leadership, citizenship and life skills" (National 4-H Council website, 2006), and the Boys \& Girls Clubs focuses on "promoting and enhancing the development of boys and girls by instilling a sense of competence, usefulness, belonging and influence" (Boys \& Girls Clubs of America website, 2006). With a majority of youth participating in some type of sports activity, it is important for all sports programs to begin establishing an activity setting that, while continuing to cultivate skill-specific learning and mastery, also stresses some broader goals and values such as cooperative community-building.

In fact, given such diversity in youth activity participation, and the benefits of multiple activity settings, it may serve youth better if practitioners of each program begin to think and work collaboratively across such programs in trying to enhance the development of youth. Of course, this collaboration is much easier to suggest than to accomplish, especially given the competitiveness surrounding the funding mechanisms that support these programs. While it is not within the scope of this paper to discuss the different ways OST activity programs can collaborate, a significant starting point would be for programs to assess how many of their youth are participating in other programs and what sorts of skills or character development the programs aim to encourage. Ideally, this collaboration would help activity program leaders to 
encourage further development of important skills cultivated in other activity contexts and to design unique opportunities that nurture additional important skill sets that are complementary to the interests and skill levels of participating youth. Such collaboration would ensure that activity programs addressed the interests of a diversity of youth, and that youth would benefit from whatever activity program opportunities available to them.

Accounting for such variation in participation is a first step toward clarifying how sports participation can be used to promote PYD. Further research that examines:

1. differences in the quality of the sports programs offered;

2. school, family, and youth assets/disadvantages linked to both adolescents' involvement in sports and other OST activities and their overall developmental trajectories, and;

3. within-person changes in the positive functioning of youth who get involved and stay involved in a sports activity pattern throughout the adolescent years, is needed to gain a better understanding of the relation between sports participation and youth functioning.

Such research, in turn, will help practitioners and policymakers effectively use sports as a tool in promoting PYD. 


\section{References}

Bachman, J.G., \& Schulenberg, J. (1993). How part-time work intensity relates to drug use, problem behavior, time use, and satisfaction among high school seniors: Are these consequences or merely correlates? Developmental Psychology, 29, 220-235.

Barber, B. L., Eccles, J. S., \& Stone, M. R. (2001). Whatever happened to the Jock, the Brain, and the Princess? Young adult pathways linked to adolescent activity involvement and social identity. Journal of Adolescent Research, 16, 429-455.

Bartko, W. T., \& Eccles, J. S. (2003). Adolescent participation in structured and unstructured activities: A person-oriented analysis. Journal of Youth and Adolescence, 32(4), 233-241.

Boys \& Girls Club of America (2006). Our mission. Retrieved September 9, 2006 from http://www.bgca.org/whoweare/mission.asp.

Chaskin, R., \& Baker, S. (2006). Negotiating among opportunity and restraint: The participation of young people in out-of-school time activities. Chicago: Chapin Hall Center for Children, University of Chicago.

Eccles, J.S., Barber, B.L., Stone, M., \& Hunt, J. (2003). Extracurricular activities and adolescent development. Journal of Social Issues, 59, 4, 865-889.

Ewing, M., Seefeldt, V., \& Brown, T. (1996). The role of organized sport in the education and health of American children and youth. (Available from the Carnegie Corporation of New York, 437 Madison Avenue, New York, NY 10022).

Jelicic, H., Bobek, D., Phelps, E., Lerner, J. V., Lerner, R. M. (In press). Using positive youth development to predict contribution and risk behaviors in early adolescence: Findings from the first two waves of the 4-H Study of Positive Youth Development. International Journal of Behavioral Development.

Larson, R. W., Hansen, D., \& Moneta, G. (2006). Differing profiles of developmental experiences across types of organized youth activities. Developmental Psychology, 42(5), 849-863.

Larson, R., \& Verma, S. (1999). How children and adolescents spend time across cultural settings of the world: Work, play and developmental opportunities. Psychological Bulletin, 125, 701-736.

Lerner, R.M., Lerner, J.V., Almerigi, J., et al. (2005). Positive youth development, participation in community youth development programs, and community contributions of fifth grade adolescents: Findings from the first wave of the 4-H Study of Positive Youth Development. Journal of Early Adolescence, 25(1).

Mahoney, J. (2000). School extracurricular activity participation as a moderator in the development of antisocial patterns. Child Development, 71, 502-516.

Mahoney, J., Larson, R., \& Eccles, J. (Eds.). (2005). Organized activities as contexts of development: Extracurricular activities, after-school and community programs. Hillsdale, NJ: Lawrence Erlbaum Associates. 
Miller, K.E., Sabo, D.F., Farrell, M.P., Barnes, G.M., \& Melnick, M.J. (1998). Athletic participation and sexual behavior in adolescents: The different worlds of boys and girls. Journal of Health and Social Behavior, 39, 108-123.

National 4-H Council (2006). Retrived September 9, 2006 from http://www.fourhcouncil.edu/. Page, R.M., Hammermeister, J., Scanlon, A., \& Gilbert, L. (1998). Is school sports participation a protective factor against adolescent health risk behaviors? Journal of Health Education, 29, 186-192.

Page, R.M., Hammermeister, J., Scanlon, A., \& Gilbert, L. (1998). Is school sports participation a protective factor against adolescent health risk behaviors? Journal of Health Education, 29, 186-192.

Peck, S.C., Roeser, R.W., \& Zarrett, N., (in press). Exploring the roles of extracurricular activity quantity and quality in the educational resilience of vulnerable adolescents: Variable- and pattern-centered approaches. Journal of Social Issues.

Posner, J.K., \& Vandell, D.L. (1999). After-school activities and the development of low-income urban children: A longitudinal study. Developmental Psychology, 35, 868-879.

Radloff, L. S. (1977). The CES-D scale: A self-report depression scale for research in the general population. Applied Psychological Measurement, 1, 385-401.

Shanahan, M. J. \& Flaherty, B. P. (2001). Dynamic Development of time use in adolescence [Special issue]. Child Development, 72(2), 385-401.

Theokas, C., Lerner, J. V., Lerner, R.M. \& Phelps, E. (2006). Cacophony and change in youth after school activities: Implications for development and practice from the 4-H Study of Positive Youth Development. Journal of Youth Development: Bridging Research and Practice, 1(1). Retrieved June 29, 2006 from http://www.nae4ha.org/directory/iyd/about.html.

The Woman's Sports Foundation (2001). Health risks and the teen athlete. Available at: http://womenssportsfoundation.org. Accessed July, 132005.

Ward, J.H., (1963). Hierarchical grouping to optimize an objective function. Journal of the American Statistical Association, 58, 236-244.

Zaff, J.F., Moore, K.A., Papillo, A.R., \& Williams, S. (2003). Implications of extracurricular activity participation during adolescence on positive outcomes. Journal of Adolescent Research, 18.

Zarrett, N. R. (2007). The dynamic relation between out-of-school activities and adolescent development (Doctoral dissertation, University of Michigan, 2006). Dissertation Abstracts International, 67(10).

(C) Copyright of Journal of Youth Development Bridging Research and Practice. Content may not be copied or emailed to multiple sites or posted to a listserv without copyright holder's express written permission. However, users may print, download or email articles for individual use. 